\title{
PRENSA Y OPINIÓN PÚBLICA FRENTE A LAS CONVERSACIONES CHILENO-BOLIVIANAS DE 1950 ${ }^{1}$
}

\author{
PRESS AND PUBLIC OPINION TOWARDS THE CHILEAN-BOLIVIAN \\ CONVERSATIONS OF 1950
}

\author{
Milton Cortés Díaz*
}

\begin{abstract}
Este artículo analiza la reacción de la prensa y la opinión pública chilena frente a las conversaciones chileno-bolivianas de 1950, en las que se exploró una posible solución a la aspiración boliviana de obtener una salida al mar. Postulamos que esta reacción fue uno de los principales factores en el fracaso de las conversaciones, ya que el creciente rechazo en contra de ellas le restó toda legitimidad a una posible cesión territorial, junto con provocar una reacción similar en la opinión pública boliviana y peruana.

Palabra claves: Relaciones chileno-bolivianas, factores internos de la política exterior, prensa y opinión pública.
\end{abstract}

This Article analyses the reaction of the Chilean press and public opinion towards the Chilean-Bolivian conversations of 1950, in which a possible solution for the Bolivian aspiration for a sea outlet was explored. We postulate that this reaction was one of the principal factors in the failure of the conversations, as the growing backlash against it rested any legitimacy for a possible territorial cession, and provoked similar reactions in the Bolivian and Peruvian public opinion.

Key words: Chilean-Bolivian relations, Internal factors in foreign policy, press and public opinion.

\section{Introducción}

La conversaciones chileno-bolivianas de 1950 fueron uno de los principales hitos de la relación bilateral entre los dos países durante el siglo XX. En ella, ambos gobiernos buscaron abrir una negociación que resolviese la aspiración portuaria de Bolivia y entregase a Chile compensaciones no territoriales que satisficieran sus intereses.

En este trabajo presentamos la hipótesis de que uno de los principales factores en el fracaso de estas gestiones fue la reacción de la prensa y la opinión pública chilena frente a las tratativas, que impidieron al gobierno de Gabriel González Videla llevarlas adelante. Ello porque, al ser Chile una democracia liberal, los medios y la opinión pública jugaban un rol importante en la dirección de la política exterior. No en forma directa, puesto que este rol recaía en el Presidente y la Cancillería, sino que actuaba estableciendo límites -aun cuando estos sean generales y poco específicos- ante las posibles políticas exteriores a seguir, mediante su apoyo o rechazo (Risse-Kappen, 1991). En el caso de Chile, quedó de manifiesto que la posibilidad de una cesión territorial a Bolivia quedaba fuera de estos límites. Sin el apoyo de la prensa y la opinión pública, el Presidente no solo tendría dificultades para justificar la legitimidad de su política, sino que tampoco encontraría apoyo en los partidos, los que debían responder a la opinión de la ciudadanía cada cuatro años en las elecciones parlamentarias.

Para demostrar cómo se fue formando esta oposición a las gestiones en los medios, nuestra metodología se ha basado en una exploración amplia de los archivos de prensa, no limitándonos a la gran prensa nacional, con sus variados colores políticos, sino que además hemos integrado periódicos con una orientación más "popular", como Las Noticias Gráficas, y prensa de las provincias afectadas, donde el tema se siguió con particular pasión. En el caso de la opinión pública hay una dificultad mayor, ya que en esta época se carece de encuestas que den cuenta de forma directa de su parecer. Para salvar este escollo, nos centraremos en el caso que tuvo mayor atención durante esta controversia, la reacción de la opinión pública ariqueña, que se manifestó directamente, en las calles, para oponerse a esta medida.

El interés en el factor de la prensa y la opinión pública en las gestiones no es completamente

\footnotetext{
* Programa de Doctorado en Estudios Americanos de la Universidad de Santiago de Chile. Centro de Extensión y Estudios de la Universidad San Sebastián. Santiago, Chile. Correo electrónico: milton.cortes@usach.cl
} 
nuevo, ya había sido tratado, aunque sin mucha profundidad o extensión, por algunos autores previos. Oscar Espinosa Moraga da cuenta que las gestiones provocaron una explosión del sentimiento popular en contra de la cesión de un corredor, afirmando que "una ola de protestas de norte a sur pareció ahogar al país entero. Las viejas heridas no suficientemente cicatrizadas, se habían abierto destilando los antiguos rencores de la Guerra del Pacífico" (Espinosa Moraga, 1965:598). Jaime Eyzaguirre en su investigación afirma que "en Chile la opinión pública reaccionó también con energía ante la posible entrega de una franja de territorio nacional a Bolivia. La prensa, la radio y el Congreso recogieron estas actitudes hostiles" (Eyzaguirre, 1967:292). Aunque estas obras son valiosas, establecen una perspectiva demasiado simple y retrospectiva, que la opinión pública chilena se manifestó unívoca e inmediatamente en contra de las gestiones. En este trabajo buscamos demostrar que esta visión no da cuenta de la complejidad de la reacción chilena, que partió con posiciones en favor, en contra y una gran parte todavía indecisa, pero el desarrollo de los acontecimientos y la incapacidad del gobierno para responder a las inquietudes de la ciudadanía, llevó a que triunfase una narrativa que rechazaba toda posible cesión territorial a Bolivia, que en un primer momento había sido minoritaria.

Algunas investigaciones ya han abordado el tema de las opiniones divergentes frente a las relaciones con Bolivia. Respecto de las conversaciones de 1950 en específico, se encuentra el trabajo de Ovando y González (2012: 461-492), que trata de la reacción iquiqueña, favorable a una posible solución de la aspiración portuaria en vista de los beneficios que podría llevar a la provincia y para alcanzar una mayor integración con Bolivia. No se pueden dejar de mencionar otros trabajos que analizan las conversaciones de 1950, como lo son Guachalla (1976), Carrasco (1991:241-247), Figueroa (1992:58-68), Pinochet de la Barra (2004:55-61), Prudencio (2007) y Cortés (2015), aunque el énfasis de estos se encuentra sobre todo en las gestiones diplomáticas. Mención aparte merece el trabajo de Alberto Ostria (1998), uno de los protagonistas de los hechos, quien da un detallado recuento, desde el punto de vista boliviano, de las gestiones, reproduciendo numerosos documentos, incluyendo algunos de prensa, tanto chilena como boliviana.

\section{Breve síntesis de las gestiones}

Las gestiones acerca del corredor se desarrollaron en Santiago, siendo la parte boliviana representada por el embajador Alberto Ostria Gutiérrez y la chilena por el presidente Gabriel González Videla y sus ministros de Relaciones Exteriores. A pesar de que estas conversaciones se desarrollaron a lo largo de dos años, de junio de 1948 a junio de 1950, en la práctica el elemento central había sido determinado de antemano en las conversaciones previas entre Ostria y González Videla. Así, en la primera de sus reuniones el mandatario le expresó al embajador que si bien en esas conversaciones informales se había desechado terminantemente la idea de ceder Arica, "no se había negado a considerar la posibilidad de llegar a un acuerdo con ese país por el cual se le cediera, mediante compensaciones, una franja de terreno al norte de Arica, que permitiera a Bolivia su salida al mar" (Archivo Nacional, Fondo Germán Vergara Donoso, Vol. 31, Memorándum Confidencial, ff. 57).

En los dos años siguientes se discutió el procedimiento a seguir, de cuántas notas se intercambiarían y cuál sería su contenido. El proceso se enlenteció en varias oportunidades, con motivo de las elecciones parlamentarias de 1949, ya que González Videla no deseaba que el tema boliviano fuese motivo de controversia electoral, y los continuos retrasos de la Cancillería boliviana para responder requerimientos de Ostria y su insistencia por mantener la cesión de Arica dentro de la discusión. Finalmente, en 1950, los dos países intercambiaron notas diplomáticas. En su parte medular, la nota boliviana decía:

(T)engo a honra proponer a V.E. que los Gobiernos de Bolivia y Chile ingresen formalmente a una negociación directa para satisfacer la fundamental necesidad boliviana de obtener una salida propia y soberana al océano Pacífico, resolviendo así el problema de la mediterraneidad de Bolivia sobre bases que consulten las recíprocas conveniencias y los verdaderos intereses de ambos pueblos (Ministerio de Relaciones Exteriores, 1952:73).

Y respondía la chilena:

En la presente oportunidad tengo el honor de expresar a Vuestra Excelencia que mi Gobierno será consecuente con esa posición 
y que animado de un espíritu de fraternal amistad hacia Bolivia, está llano a entrar formalmente en una negociación directa destinada a buscar la fórmula que pueda hacer posible dar a Bolivia una salida propia y soberana al océano Pacífico, y a Chile obtener compensaciones que no tengan carácter territorial y que consulten efectivamente sus intereses (Ministerio de Relaciones Exteriores, 1952:73).

Como hemos establecido en un trabajo previo (Cortés, 2015), el objetivo de estas notas iba más allá de resolver la aspiración boliviana. Se esperaba aumentar la influencia chilena sobre Bolivia y ayudar a la estabilidad del régimen del altiplano, amenazado por las actividades insurreccionales del Movimiento Nacionalista Revolucionario, que La Moneda percibía era parte de un movimiento autoritario transnacional que incluía a la Argentina de Perón y el Perú de Odría. De triunfar los movimentistas en Bolivia, Chile quedaría atrapado bajo un "cerco totalitario", que podría obligarle a ceder un puerto a Bolivia en circunstancias desventajosas, lo que le daba un incentivo a González Videla para resolver pronto la aspiración boliviana.

\section{La revelación de las notas por parte de la revista Ercilla}

Correspondió a la revista Ercilla la revelación de las gestiones a la opinión pública, ya que el gobierno chileno no había dado indicio alguno de que se estuviese tratando cuestión alguna con Bolivia. En su edición del 11 de julio de 1950 publicó detalles acerca del posible corredor. En su parte medular el artículo decía:

\section{La tradicional y sentida reivindicación de \\ Bolivia que busca una salida al mar, quiere solucionar GGV: le ofrece una franja de 10 kilómetros de ancho $(1.750 \mathrm{kms} .2$ de superficie total), que baje de la cordillera al Pacífico, a 32 kilómetros al norte de Arica. El "Corredor Boliviano" irá pegado a la actual "Línea de la Concordia", establecido en 1929. Chile dejaría de limitar con el Perú (Ercilla, 11 de julio de 1950).}

La revista afirmaba que, como compensación al territorio cedido, Bolivia permitiría a Chile y Perú el uso de las aguas del lago Titicaca, para crear fuerza hidroeléctrica y regadío para los valles del norte de Chile y sur del Perú. También se dijo que Estados Unidos entregaría los empréstitos para llevar a cabo tanto las obras de irrigación como la construcción del puerto de Bolivia. Si bien la revista remarcaba la noticia en cuanto golpe noticioso, su posición ante las gestiones fue cautelosamente optimista. En su reflexión final, afirmaba: "Si todo esto puede realizarse en la forma que se piensa con positivos beneficios y a la vez se quitan piedras del rumbo político internacional, Chile se encuentra en la antesala de una de las medidas de gobierno más trascendentales de su historia" (Ercilla, 11 de julio de 1950). Pero también daba cuenta que el éxito de las gestiones pondría en interrogación el futuro de Arica, afirmando que "Un puerto extranjero a su vera significa su muerte", al reemplazarse sus funciones como puerto para las mercaderías del altiplano.

El presidente González Videla trató de calmar la controversia y desmentir varias de las informaciones. En una entrevista a la revista Vea, afirmó:

\begin{abstract}
Hay que aclarar las cosas. E1 Gobierno no ha resuelto nada sobre este tema. Lo único verdadero es que, consecuente con la tradición de la Cancillería chilena, y ratificando mi profundo espíritu americanista, nunca me he negado a conversar sobre la aspiración portuaria de Bolivia. (...) Me hago un deber, sí, en declarar a los ciudadanos de mi patria que el Presidente de Chile está llano a abrir esas conversaciones con dos condiciones irrevocables: $1^{\circ}$. Que no se planteen ellas en terreno de la revisión de tratados, porque en ese aspecto no tenemos ningún problema pendiente con Bolivia. Los tratados suscritos se cumplieron ya en el tiempo, y hoy son solo hechos históricos. (...) $2^{\circ}$. La segunda gran condición es la de que todas las posibles conferencias a que dé lugar el estudio del problema de la mediterraneidad de Bolivia deben contar con el previo acuerdo del Perú, porque así lo dispone el Protocolo Complementario del Tratado chileno-peruano, suscrito en Lima el 3 de julio de 1929. (Vea, 19 de julio de 1950)
\end{abstract}

Insistió en que el corazón de la gestión era que su gobierno estaba dispuesto a conversar amistosamente con el gobierno boliviano y que el resto eran falsedades. Daba como ejemplo que se hablaba de una faja de 32 kilómetros, cuando 
en realidad la faja al norte de Arica era de apenas de 10 kilómetros hasta llegar la frontera con Perú.

\section{La prensa de Santiago frente al corredor}

La mayoría de la gran prensa santiaguina reaccionó a las informaciones de la revista Ercilla con mucha precaución, esperando a que surgieran informaciones oficiales para manifestarse respecto de ella. El Mercurio, de tendencia liberal sin afiliación partidaria, demoró más de una semana la revelación al comentar el tema en su editorial del 19 de julio. Defendió sobre todo el principio del respeto a los tratados internacionales, aunque aceptando que ello no impedía que se pudiesen estudiar nuevos entendimientos, pero que toda gestión sería más exitosa "si se proyecta hacia realidades y no hacia utopías tan gentiles como engañadoras" (El Mercurio, 19 de julio de 1950). Al día siguiente tocó opinar a El Diario Ilustrado, de orientación conservadora, que recordó que era tradición de Chile no negase "a oír los requerimientos de nuestros vecinos, ni a estudiar alguna fórmula que, dentro del cumplimiento de los tratados internacionales y en términos en que no se perjudiquen nuestros intereses, pudiera dar satisfacción a esos anhelos" (El Diario Ilustrado, 20 de julio de 1950). El diario conservador esperaba que las alarmas producidas por este tema fuesen infundadas, ya que las cuestiones territoriales debían ser estudiadas con seriedad y tomando en cuenta a la opinión nacional.

El periódico que mayor apoyo dio a las gestiones fue el oficialista La Nación. Al momento de estallar la noticia, defendió que el gobierno:

\section{no ha hecho otra cosa que mantener la tradición invariable que ha seguido en sus relaciones con Bolivia desde el Tratado de 1904 o sea, la de no negarse jamás a escu- char proposiciones directas del Gobierno amigo sobre sus anhelos portuarios en el Pacífico, y la de repudiar con toda firmeza cualquier intento de imposición al respecto, o de intervención de terceras potencias o entidades de carácter internacional (La Nación, 23 de julio de 1950).}

Acusó la existencia de intentos de tergiversar las gestiones, promovidas por motivos políticos para crear una polémica artificial (La Nación, 5 de agosto de 1950).

Hasta el diario nacionalista El Imparcial reaccionó con mesura, afirmando que era difícil pronunciarse respecto de un tema del que no existía información oficial, pero viendo como positivas las nuevas tendencias mundiales en favor de la cooperación e integración. Uno de sus editoriales destaca por reflejar una apertura a ciertas ideas más idealistas del orden mundial, que superase las concepciones tradicionales de soberanía, en línea con el proceso europeo y la labor de la ONU:

Las naciones, tan celosas de sus derechos
individuales, hasta antes de la última
guerra, han comprendido, bajo el peso de
la conflagración, que su particular interés,
como el de los individuos dentro de cada
Estado, debe ceder parte de su egoísmo
para dejar paso al bien común (...) Todo
esto representa en mayor o menor grado,
renunciamientos al antiguo concepto de
soberanía; pero, ello para dar paso a una
nueva y audaz visión de la vida internacio-
nal basada en la unión de los recursos y
los intereses de distintos países, en forma
de ayudarse mutuamente y de construir
la futura paz mundial sobre el cimiento
de un mejor y más regular estándar de
vida de los pueblos (El Imparcial, 27 de
julio de 1950).

Los editoriales de la gran prensa tuvieron en común una posición precavida frente a las gestiones, desestimando los rumores -ninguno discutió el corredor en cuanto tal-y comentando principalmente las informaciones oficiales. Pocos se refirieron directamente al fondo de la cuestión, si debía o no cederse territorio a Bolivia, concentrándose en el hecho de la apertura de negociaciones. Pero hubo excepciones que se mostraron más abiertamente partidarias, tanto en favor y en contra, respecto de la aspiración boliviana.

Una de estas excepciones fue el diario sensacionalista Las Noticias Gráficas, quien de inmediato se mostró en contra de las gestiones y buscó tocar aspectos sensibles de las relaciones chileno-bolivianas para movilizar a la opinión pública en su contra. Su mejor truco fue dar voz a los veteranos de la Guerra del Pacífico, estos expresaron que el país no podía entregar lo que se ganó con sangre. 
Varios apelaron a la memoria de sus compañeros de armas caídos en combate y que la cesión del corredor convertiría su sacrificio en vano. Entre las frases más duras, uno de los veteranos expresó que "Solo los traidores y vende patrias pueden pensar en ceder a Bolivia lo que ganó Chile con su honor, corazón y pana" (Las Noticias Gráficas, 13 de julio de 1950). En otra edición se entrevistó a las hijas de los soldados del 79, quienes igualmente calificaron a las gestiones como una infamia y un atentado a la chilenidad (Las Noticias Gráficas, 14 de julio de 195). Se recurrió también a la enemistad chilenoboliviana prevaleciente en La Paz, recordando la enseñanza en el altiplano de cánticos antichilenos a los escolares, que llamaban a tomar revancha contra Chile y a vencer en una nueva guerra (Las Noticias Gráficas, 16 de agosto de 1950).

En el sentido contrario, de apoyo a las gestiones, encontramos al diario El Tarapacá de Iquique, una de las ciudades que más se beneficiaría de las posibles compensaciones que ofrecería Bolivia. Este diario reconocía la existencia de una gran oposición al proyecto en la vecina Arica, en donde se temía que el puerto boliviano provocase el fin del tránsito de mercaderías bolivianas a la ciudad, pero el diario argumentó que esa posición, al oponerse a todo estudio al respecto, "no tiene consistencia, puesto que se basa en una apreciación egoísta, sentimental de pequeño interés". Se replicaba que Arica también obtendría beneficios, ya que, al estar cerca de un puerto extranjero de gran importancia, se crearían nuevas fuentes para su vida económica. Defendió las posibilidades de regadío y electrificación en las zonas de Tarapacá de las acusaciones de ser proyectos utópicos, porque para la técnica moderna y el capital no había, en ese momento, nada imposible (El Tarapacá, 6 de agosto de 1950).

Una de las primeras figuras públicas en pronunciarse a favor de las gestiones fue el rector de la Universidad de Chile, Juvenal Hernández. Decía que la alarma de los ariqueños no se justificaba, ya que la gestión podría proporcionar grandes beneficios agrícolas para la provincia de Tarapacá, que la convertiría en una de las zonas productoras más ricas del país (El Tarapacá, 15 de julio de 1950). Sin embargo, con el desenvolvimiento de las gestiones, el rector consideró que estas se habían llevado a cabo de una forma desafortunada, especialmente en consideración de la reacción negativa que había surgido en la ciudadanía, lo que habría colocado a Chile en una situación desfavorable en el continente, "por cuanto de antemano se sabe que tal proyecto es irrealizable e inadmisible, en lo que a Chile se refiere" (La Gaceta, 5 de septiembre de 1950).

Joaquín Edwards Bello publicó una columna favorable a conceder a Bolivia una salida al mar, que vio como un reflejo de la enorme generosidad de Chile, recordando de paso que

\section{ningún país en el mundo ha devuelto lo que se conquistó en el siglo XIX o antes del XIX (...) Está bien que concedamos una salida a Bolivia, pero sin ingenuidad: no esperemos agradecimiento. En cambio, tendremos agua para mojar la lengua seca del norte y un puerto construido por norteamericanos, excelentes vecinos y amigos (La Nación, 22 de julio de 1950).}

Las gestiones también tuvieron grandes detractores entre los hombres públicos. Quizás el de mayor prestigio fue el excanciller Conrado Ríos Gallardo, quien criticó al gobierno por ignorar al Perú en estas gestiones, en contravención del Tratado de 1929, al privilegiar en cambio a Washington. Auguraba que si el corredor se materializaba: "Arica sería condenada a morir sin gloria, aun cuando se encuentre recostada al pie del morro legendario". Pero sus temores concernían al precedente que crearía tal cesión:

\section{Si empezamos hoy a conceder corredores hacia el Pacífico (...) creamos un antece- dente que nadie sabe a dónde nos puede conducir en el provenir. Bolivia también sale por Antofagasta. ¿Regaremos otras pampas y entregaremos otro corredor? (...) iLos pueblos tienen el deber de pensar más en el mañana que en el presente! ( $L a$ Gaceta, 24 de julio de 1950).}

Crítico de la gestión del gobierno, por estar en medio la integridad del patrimonio nacional, dijo que el Presidente "ha confundido las relaciones entre los Estados con las relaciones entre los partidos políticos. No se asusten, el arte de S. E. para manejarse en la política interna es de una agilidad sorprendente; yo creo, sin embargo, que la misma agilidad usada en la política internacional es un peligro". También se refirió ácidamente al hecho de negociar con un gobierno tan débil como el boliviano: "¡Yo no sé a qué se debe este afán de entender con 
un Gobierno como el de Bolivia, que cada quince días amanece con una revolución sofocada!" (Vea, 26 de julio de 1950).

\section{La opinión pública movilizada: el caso de Arica e Iquique}

En ninguna otra parte del país la reacción pública fue más contraria a las gestiones que en Arica. Estas fueron percibidas como una amenaza a la existencia de la ciudad, ya sea porque podría ser el primer paso hacia una anexión boliviana o porque significaría la ruina económica del puerto. El tema no fue una cuestión discutida solo por la prensa y los políticos, sino que afectaba también al hombre de la calle. El diario El Pacífico describió el ambiente en la ciudad al conocerse la noticia:

\section{En todos los círculos de la localidad, en los corrillos callejeros en los bares, insti- tuciones especiales, mercados $y$, en fin, en cualquier sitio de Arica, la conversación de rigor gira en torno a este asunto, emitiendo cada cual su opinión al respecto. Pero la creencia que ha arraigado más en el ánimo de los pobladores es aquí la versión que se refiere a una posible entrega de Arica a Bolivia (El Pacífico, 15 de julio de 1950).}

El periódico La Gaceta expresó los temores acerca de lo que sucedería con la ciudad en caso de suscribirse el acuerdo, según las bases publicadas por Ercilla: “El ‘Corredor boliviano' significaría la muerte a muy corto plazo, por asfixia económica, del puerto de Arica, al transformarse gradualmente en una simple caleta". Temían un destino parecido al de Pisagua, que pasó de ser uno de los grandes puertos de embarque de salitre a perder toda importancia. Arica, decía La Gaceta, "depende en su vida económica casi totalmente del movimiento ferroviario internacional a Bolivia, el que desde hace algún tiempo ha venido disminuyendo alarmantemente en su volumen, acentuando la crisis que se advierte en el desenvolvimiento económico-comercial ariqueño" (La Gaceta, 15 de julio de 1950). La posibilidad de regar la Pampa del Tamarugal se consideraba dudosa, ya que nadie se había detenido a considerar sus aspectos técnicos y económicos (La Gaceta, 18 de julio de 1950).

La primera demostración en masa del repudio a las gestiones ocurrió el 23 de julio, en una manifestación en el Parque Vicuña Mackenna, con una asistencia que se estimó en tres mil personas, de un total aproximado de 23 mil habitantes. Antes de reunirse, una columna de gran longitud salió del local del Sindicato de Panificadores, portando banderas nacionales y carteles con frases como "La Patria no se vende, menos la tierra de Arica" y "No soltaremos el Morro". Hablaron en la ocasión oradores del Partido Liberal, Falange, Socialista Popular y Frente Nacional Democrático, además de líderes sindicales de diversas profesiones. En ella no solo se repudió al corredor, sino además se pidió una ley que declarase a Arica puerto libre, que se concebía como la mejor manera para lograr su efectivo progreso (La Gaceta, 24 de julio de 1950).

Las manifestaciones no se detuvieron. El 30 de julio se realizó un cabildo abierto en el estadio de la ciudad, a la que se reportó la asistencia de 5 mil personas. Realizaron discursos varias personalidades, desde el alcalde de la ciudad, el gobernador del departamento y los representantes de Arica en el Parlamento, entre otros. Muchos de los discursos se dirigieron contra el centralismo de Santiago y las peligrosas consecuencias de las conversaciones, así el senador Radomiro Tomic expresó:

Cuando se piensa y habla allá en Santiago, sobre la entrega de una granja de $10 \mathrm{ki}$ lómetros de ancho, la gran mayoría dice ¿qué son 10 kilómetros? Y yo he tenido la oportunidad de escuchar este mismo interrogante, ciertamente despectivo, en los propios pasillos del Senado y la Cámara, interrogante a la cual he respondido: ¡Cuidado! Esos 10 kilómetros, a muy corto plazo puede significar para Chile el repliegue de sus fronteras hasta las márgenes del río Loa (La Gaceta, 31 de julio de 1950).

El senador radical Ángel Custodio Vásquez, extremó las medidas de resistencia que Arica podría tomar, ya que aunque esperaba que el Presidente no estuviese dispuesto a ceder parte del territorio, si esto finalmente ocurría:

para eso están ustedes, estamos nosotros, para formar una barrera infranqueable con nuestros pechos, que hoy gritan planos de emoción patriótica: "No podemos ceder, no debemos regalar una sola pulgada del 
patrimonio nacional” (...) Y si llega el momento en que tengamos que defender con el arma en el brazo nuestro amado suelo, podéis estar seguros que estará junto a ustedes, codo a codo, este vuestro viejo parlamentario (La Gaceta, $31 \mathrm{de}$ julio de 1950).

Por su parte, el diputado Oscar Quina relató una conversación que sostuvo con el presidente González Videla, quien le habría asegurado que "los ariqueños podrían estar seguros de que no se llegará el caso de ceder una sola pulgada del suelo patrio", a lo que Quina habría respondido que él, como ariqueño, rechazaría tal proyecto de ser presentado en el Congreso, aun a riesgo de ser expulsado de su partido (La Gaceta, 31 de julio de 1950). No obstante, su intervención fue pifiada , al proponer que se realizase un plebiscito para conocer la opinión del pueblo chileno respecto del corredor, cosa que no agradó en nada a los ariqueños (Las Noticias Gráficas, 1 de agosto de 1950).

Las presiones no pasaron inadvertidas por el resto del país. En particular el Partido Radical, que en un primer momento había dicho que respetaría las prerrogativas constitucionales del mandatario por las presiones de la Asamblea de Arica efectuó una declaración en que se aclaraba que "El CEN es contrario al pensamiento de entrega de territorio a pesar de las compensaciones que pudiera obtener" y que las prerrogativas presidenciales a las que se referían era "a oír aspiraciones de países con los cuales [Chile] mantiene cordiales relaciones", insistiendo en que las gestiones del gobierno se habían limitado a eso, a escuchar a Bolivia y que las conversaciones debían darse por terminadas tras oír las explicaciones del Canciller (La Gaceta, 5 de agosto de 1950).

El 9 de agosto se dio otra demostración del pueblo de Arica, en la llamada "marcha de la integridad territorial". Esta reunió a unas 3 mil personas, estas, portando banderas chilenas, letreros, faroles y antorchas, marcharon desde el parque Vicuña Mackenna hasta el Morro. La marcha fue organizada por el presidente del Partido Liberal de Arica, quien en el discurso de ocasión pidió que "no se cometa el crimen de cercenar la más mínima parte del territorio nacional, en aras de un muy dudoso americanismo" (La Gaceta, 1 de agosto de 1950). Para colmar estos esfuerzos, el 17 de agosto se formó el Comité Pro-Defensa Permanente de Arica, constituido por diversos representantes de la ciudadanía ariqueña, la que formó varias comisiones, no solo para oponerse a las aspiraciones bolivianas sino además para alcanzar el mejoramiento económico de la provincia (La Gaceta, 18 de agosto de 1950).

Pero existió otra reacción local importante, en la dirección opuesta, en Iquique. Ya se ha visto cómo su principal periódico, El Tarapacá, se mostró favorable a las gestiones. Pero esto también trascendió a otros actores de la vida pública. Uno de ellos fue el Centro para el Progreso de Tarapacá, el que decidió enviar telegramas al gobierno y a los parlamentarios de la provincia para exponerles su pensamiento favorable a la cesión de un puerto a Bolivia a cambio del uso de las aguas del Titicaca al norte de Chile. Además, esperaban que la construcción del puerto, cuyo costo se cifraba en cien millones de dólares y diez años de construcción, entonaría las industrias del salitre, cobre y estaño, pudiendo estabilizar el futuro de la zona norte (El Tarapacá, 20 de julio de 1950). La misma posición tomó la Cámara de Comercio de la ciudad, que llamó a que "todas las fuerzas vivas de la Provincia (...) apoyen y alienten al Supremo Gobierno para que prosiga sin dificultades las gestiones para hacer realidad el proyecto del corredor para Bolivia con sus compensaciones correspondientes" (El Tarapacá, 26 de julio de 1950).

Un exintendente de la provincia, Raúl Kinast, inclusive dijo que sería preferible incluir en el territorio cedido a la misma Arica, asegurando que esta "se transformaría en una especie de capital de la República de Bolivia. Imagínese lo que significa que todo el movimiento comercial de un país más grande que Chile saliera por un solo puerto. Creo que en poco tiempo Arica se transformaría en uno de los puertos más grandes de la Costa del Pacífico" (El Tarapacá, 29 de julio de 1950). Comentarios como estos ayudaban a exacerbar la ya histórica rivalidad entre Arica e Iquique.

\section{Reacción de la opinión pública en Bolivia}

Así como es errado creer que la opinión pública chilena se manifestara siempre y automáticamente como contraria a la aspiración marítima, la misma lógica puede llevar a pensar que en Bolivia cualquier posibilidad de solución sería recogida con algarabía. En realidad, la reacción en el altiplano fue tan compleja como la chilena, con visiones plurales y divergentes.

Aunque al principio las reacciones fueron positivas en el altiplano, existía cierto malestar por el concepto 
de obtener un corredor, en contraposición a la cesión de Arica. Un editorial del El País de Cochabamba, si bien felicitaba la iniciativa del mandatario chileno, también llamaba a ejercer presión, por medio de un boicot, para que con la venia del Perú se vendiese Arica a Chile (citado en La Gaceta, 8 de agosto de 1950). El Junín de Sucre también compartía esa posición, explicando que la construcción de un puerto significaría gastos tan enormes que Bolivia no estaría en condiciones de realizarlos y que por ello el corredor solo tendría un valor simbólico (citado en La Gaceta, 5 de agosto de 1950).

Demetrio Canelas, afamado escritor y exministro de relaciones exteriores, publicó un artículo en el periódico paceño Última Hora en que se atacaba las gestiones en su fondo, diciendo que "esta idea, en el fondo, no busca la solución del problema, sino que, más bien, tiende a desviar y perturbar los espíritus, con el señuelo del 'puerto propio' cuando en realidad lo que se intenta es sustituir el puerto propio por un puerto impropio, que ni siquiera se sabe si existe" (citado en La Gaceta, 10 de agosto de 1950).

De todas las opiniones surgidas en el altiplano, la que más tendría resonancia fue la del viejo político Franz Tamayo, publicada en Última Hora. En ella Tamayo haría el mayor ataque contra el uso de las aguas del Titicaca a cambio de un corredor, calificándolo como un plagio tardío y pobre del famoso corredor polaco. Arguyó que el corredor no era más que una trampa, equivalente al impuesto de los 10 centavos que inició la guerra del Pacífico, afirmando sin ambages que Chile necesitaba urgentemente entrar en guerra con Bolivia, y que la gestión del corredor otorgaría la excusa perfecta: "La oferta significa el grito agónico y velado ante la ruina inminente. La sola salvación de Chile es el zarpazo sobre el corazón de Bolivia. (...) Chile necesita urgentemente volver al estado de guerra contra Bolivia. Para ello es preciso preparar un campo sedicente jurídico que justifique la nueva conquista" (citado en Ostria, 1998: 87).

Pero asimismo hubo voces que defendían las gestiones en su plenitud. Hombres públicos como Tomás Elio y Casto Rojas celebraron las notas como un nuevo capítulo histórico en la política portuaria y Fernando Guachalla la calificó como la obra que correspondía encarar a la actual generación boliviana. El diario La Razón replicaba a los críticos diciendo que "Un elemental deber de patriotismo aconseja llevar el asunto con la mayor serenidad sin estridencias ni politiquerías para no malograr talvez la mejor oportunidad histórica de llegar a un entendimiento con Chile y el Perú" (citado en Ostria, 1998: 85). En otra de sus editoriales, el periódico paceño invocaba a la unidad de todos los bolivianos, diciendo que "el ideal portuario, mientras no sea alcanzado vivirá lo que vive la nación, no puede obscurecerse por las suspicacias políticas ni divisiones internas" (citado en El Mercurio, 3 de septiembre de 1950).

La experiencia en Bolivia es muy semejante a la reacción en Chile. En ambas naciones hubo posiciones diversas, pero con el desarrollo de los acontecimientos fue ganando fuerza la narrativa que expresaba que la cesión de las aguas del Titicaca era inaceptable. Al igual que en Chile, se estaba imponiendo un límite a las posibilidades de una política exterior, lo que colaboró con el fracaso de las gestiones.

\section{Vuelco de la opinión pública chilena en contra de las gestiones}

Como tras la publicación de las notas las gestiones no parecían tener ningún avance, se formó la impresión en el público de que el asunto estaba concluido. No obstante, el tema sería revivido por el presidente Harry Truman al declarar, en marzo de 1951, que le agradaba mucho un proyecto que había conversado con el Presidente de Chile, de usar las aguas del lago Titicaca para crear un vergel para Chile y Perú a cambio de un puerto para Bolivia (Ostria, 1998:148).

Las declaraciones de Truman provocaron una airada reacción en la prensa, mayormente negativa, pues se interpretaron como una forma de presión de parte de Estados Unidos. Así lo caracterizó El Diario Ilustrado, quien dijo que esta declaración del Presidente estadounidense "podría ser estimada como una presión de orden moral a favor de una determinada aspiración" (El Diario Ilustrado, 28 de marzo de 1951), mostrándose decepcionado que este tema desviase el objetivo de la Conferencia. El Imparcial, que se había mostrado relativamente favorable a las gestiones, pasó al bando contrario, expresando que "Declaraciones extemporáneas y sin suficientes explicaciones, no pueden sino rozar la sensibilidad de un pueblo como el nuestro y dar motivo a una justa aprensión" (El Imparcial, 29 de marzo de 1951).

El presidente González Videla debió realizar un discurso por radio el 29 de marzo de 1951 para 
explicarle al país que su política a Bolivia no se había apartado de la tradición, al escuchar las aspiraciones bolivianas, pero sin reconocerle derechos ni permitir la revisión de los tratados. Remarcó que las gestiones habían sido esencialmente una apertura al diálogo, sin haberse comprometido el país a nada, estando su actitud siempre guiada por un ideal americanista y de integración continental (El Mercurio, 30 de marzo de 1951).

El discurso del Presidente tenía que provocar reacciones. Hubo manifestaciones de apoyo, así, El Mercurio catalogó su exposición como "clara, precisa y circunstanciada", siguiendo la tradición diplomática nacional y sus prerrogativas constitucionales, habiéndose aclarando que la intervención de Truman había sido con un espíritu americanista y amistoso (El Mercurio, 31 de marzo de 1951). Semejante posición tomó La Nación, quien aprovechó para reforzar la imagen de González Videla como un líder democrático: "Mostrándose una vez más como un mandatario democrático, el señor González Videla no pide silencio ni cesación de las observaciones que pudieran hacerse, sino que prevalezca un espíritu patriótico, que aparte las desviaciones de la pasión y deje de lado las conveniencias políticas del momento" (La Nación, 31 de marzo de 1951). Ninguno de los dos diarios defendía una cesión territorial, sino que se limitaban a resguardar la actuación del jefe del Estado, afirmando que esta no se había apartado de la tradición diplomática.

Con un tono más crítico de la gestión del mandatario en este asunto, El Diario Ilustrado manifestó que "mientras solamente exista el antecedente negativo de que el gobierno de Chile no desea compensaciones territoriales, creemos que todo lo que se haga no conducirá a nada beneficioso y, por el contrario, conduciría a algo perjudicial, como es encender antiguos resquemores, que todo aconseja apagar y hacer tensas las relaciones entre dos pueblos" (El Diario Ilustrado, 31 de marzo de 1951). Las Noticias Gráficas público un violento editorial, diciendo que "El Presidente de la República está profundamente equivocado al creer que Chile es una simple granja de su propiedad, de la que puede disponer libremente, incluso enajenar cualquier parte de su territorio" (Las Noticias Gráficas, 30 de marzo de 1951).

En Arica nuevamente surgieron grandes manifestaciones callejeras para mostrar su repudio al corredor (La Gaceta, 6 de abril de 1951). Los discursos en esta oportunidad fueron mucho más violentos con la figura del mandatario, estando presente el tema de que se estaba vendiendo a la patria (La Gaceta, 6 de abril de 1951). Quien llevó esto al paroxismo fue el diputado Luis Undurraga, quien en su intervención en las protestas ariqueñas dijo que los parlamentarios habían sido "violentamente engañados por el Ministro de Relaciones, al asegurarnos que no existía negociación alguna que llegara a afectar la integridad del territorio nacional". Cuestionó el patriotismo del mandatario, diciendo que el presidente "ha olvidado que Arica, que el patrimonio nacional, no es una mercancía que está en venta al mejor postor (...) El solo proyecto de ceder un corredor o el puerto de Arica, es como el caso de un padre, que para tener mayores comodidades en su hogar, vendiera a una de sus hijas". Tal fue el apasionamiento del diputado, que en un momento llegó a comparar a González Videla con Nerón, Calígula y Heróstrato, diciendo del mandatario que "no deseamos que sueños de posteridad le lleguen a colocar en un plano que linda con el ridículo" ( $L a$ Gaceta, 6 de abril de 1951).

\section{Conclusiones}

Como se ha expuesto en esta investigación, las noticias acerca de las gestiones chileno-bolivianas provocaron toda clase de reacciones, de la relativa neutralidad de la gran prensa santiaguina, las opiniones favorables en Iquique y la virulenta reacción en contra del pueblo de Arica. Esta reacción no fue un mero aspecto secundario en la historia de las gestiones, sino que impactó de forma decisiva en su eventual fracaso. Esto se debió a diversos elementos, que pasamos a enumerar:

1. La filtración pertinente a las gestiones ocurrió en una etapa relativamente temprana de las mismas, al haberse apenas llegado a acuerdo respecto de las bases con las cuales empezar a negociar. Esto hizo por una parte que las gestiones quedasen paralizadas, ya que tanto el gobierno chileno como el boliviano buscaron enervar las pasiones que se habían desatado en la opinión pública, como requisito antes de seguir adelante con las conversaciones. Asimismo, esta situación impidió al presidente González Videla defender una proposición concreta para resolver la mediterraneidad boliviana, por lo que no podía asegurar beneficios para el país, 
mientras que los temores de una cesión territorial crecían en la población.

2. La publicación de Ercilla fijó dos imágenes en la opinión pública, la cesión de un corredor al norte de Arica y la compensación en forma del uso de las aguas del lago Titicaca. Si bien el primer punto está relativamente acordado en las discusiones previas, el uso de las aguas del Titicaca era solo entre muchas posibilidades de compensación, al que el gobierno boliviano nunca se comprometió, lo que no impidió que González Videla la viese como su opción favorita y la comentase inclusive con el presidente Truman. Esto causó un grave daño a las gestiones, pues fue el punto que condujo a la mayor oposición en la opinión pública de Bolivia y Perú.

3. Si bien la reacción de la gran prensa nacional fue relativamente cautelosa y hasta benigna hacia las gestiones, solo encontró un apoyo decidido en La Nación, diario de gobierno. Con el tiempo, particularmente por las declaraciones de Truman, que hacían temer una posible intervención estadounidense, varios diarios que se habían mostrado abiertos a las gestiones, como El Diario Ilustrado y El Imparcial, pasaron a la oposición del mismo. Este escaso apoyo dificultaba al Presidente en sus intentos de defender la continuidad de las gestiones, ya que la opinión pública parecía rechazarla.

4. El gobierno también se debió enfrentar a una oposición muy vigorosa, tanto desde la prensa amarilla, que inflamó el sentimiento nacionalista, como en la reacción en la ciudad de Arica, en donde no solo se manifestó la prensa, sino que gran parte de la sociedad civil, con grandes manifestaciones públicas y llamamientos a sus parlamentarios para oponerse a los planes del Presidente. Estas manifestaciones no fueron ignoradas por el resto del país e hizo que varios políticos, especialmente los representantes de la zona, se mostrasen como una gran voz opositora ante las gestiones en el Parlamento, creándose una narrativa que no tuvo contraparte entre quienes apoyaban las conversaciones, lo que facilitó su triunfo en el resto del país.

\section{Referencias Citadas}

\section{Carrasco, S.}

1991 Historia de las relaciones Chileno-Bolivianas, Editorial Universitaria, Santiago.

Cortés, $\mathrm{M}$.

2015 En torno de las conversaciones de 1950: La política hacia Bolivia de Gabriel González Videla, Si Somos Americanos, vol. $15, \mathrm{~N}^{\circ}$ 2: 149-171.

Espinosa, O.

1965 Bolivia y el mar, 1810-1964, Editorial Nascimento, Santiago.

Eyzaguirre, J.

1967 El intento de negociación chileno-boliviana de 1950 y su secuela, Editorial Jurídica de Chile, Santiago.

Figueroa, U.

1992 La demanda marítima boliviana en los foros internacionales, Andrés Bello, Santiago.

Guachalla, L. F.

1976 La cuestión portuaria y las negociaciones de 1950, La Paz, Editorial Los Amigos del Libro.

Ministerio de Relaciones Exteriores

1952 Memoria del Ministerio de Relaciones Exteriores correspondiente al año 1950, Imprenta Chile, Santiago.
Ostria, A.

1998 Apuntaciones sobre negociaciones portuarias con Chile, Archivo y Biblioteca Nacionales de Bolivia, Sucre.

Ovando, C. y González, S.

2012 La política exterior chileno-boliviana en la década de 1950 mirada desde la región de Tarapacá. Una aproximación desde el diálogo entre las teorías de las percepciones y el realismo neoclásico, Polis, vol. 11, No 32 : 461-492.

Pinochet de la Barra, $\mathrm{O}$.

2004 Chile y Bolivia: ‘hasta cuándo!, LOM Ediciones, Santiago.

Prudencio, $\mathrm{R}$

2007 La negociación de 1950 con Chile. En VI Encuentro de Historiadores, Intelectuales y Cientistas Sociales BoliviaChile: Iquique, Chile, 17 y 18 de octubre 2006, Universidad Bolivariana, Santiago.

Risse-Kappen, T.

1991 Public Opinion, Domestic Structure, and Foreign Policy in Liberal Democracies, World Politics, $\mathrm{N}^{\circ} 43$ : 479-512.

\section{Nota}

Este trabajo es parte de la tesis "Proyección interamericana de la política de 'defensa de la democracia' del presidente Gabriel González Videla”. 